$$
\begin{aligned}
& 10.0400 .27 \\
& \text { IN-46 U } \\
& 3937 \\
& 1 / 1
\end{aligned}
$$

\title{
SUBSTORM THEORIES: UNITED THEY STAND, DIVIDED THEY FALL
}

\author{
Gary M. Erickson \\ Center for Space Physics \\ Boston University \\ Boston, MA 02154
}

Revised Draft: January 4, 1995

Submitted for contribution in the

U.S. National Report to the International Union of Geodesy and Geophysics 1991-1994

(NASA-CR-197672) SUBSTORM
THEORIES: UNITED THEY STAND.
DIVIOED THEY FALL (BOSTON UnIV.)
11 p

N95-22326

Unclas

G3/46 0039377 


\section{Introduction}

Consensus on the timing and mapping of substorm features has permitted a synthesis of substorm models. Within the synthesis model the mechanism for onset of substorm expansion is still unknown. Possible mechanisms are: growth of an ion tearing mode, current disruption by a cross-field current instability, and magnetosphere-ionosphere coupling. While the synthesis model is consistent with overall substorm morphology, including near-Earth onset, none of the onset theories, taken individually, appear to account for substorm expansion onset. A grand synthesis with unification of the underlying onset theories appears necessary.

\subsection{Relevance to Space Weather Prediction}

One important element in the development of a space weather predictive capacity [see the article by $\mathrm{N}$. Maynard, this issue] is the prediction of onset of magnetospheric substorm expansions. The transfer of solar wind energy to Earth's inner magnetosphere and upper atmosphere occurs not only in a more or less directly driven fashion. Part of this transferred energy is stored in the geomagnetic tail in plasma and magnetic flux (the substorm growth phase) and is released intermittently in events known as substorm expansions. Like earthquakes and volcanoes to the lithosphere and cyclones to the troposphere, the substorm is the release of stress and stored energy in the magnetosphere, only on a much larger scale, 6 times per day, on average. While much of this energy is released away from Earth, a significant amount is injected toward Earth. This intermittent release not only results in auroral breakup and spectacular auroral displays, but can interfere with or cause damage to geosynchronous and ground-based facilities.

Substorm expansions are characterized by the sudden dipolarization of previously stressed (taillike), near-Earth, plasma-sheet flux tubes, which energizes and injects plasma into the geosynchronous environment. These high fluxes of energetic particles can interfere with the performance of geosynchronous spacecraft or cause them permanent damage. The dipolarization is associated with a diversion of roughly a million amps of dawn-to-dusk plasma sheet drift current along magnetic field lines into the auroral ionosphere as the substorm current wedge. Ionospheric densities and temperatures are increased, which can interfere with communications, radars, and lowaltitude spacecraft. The sudden intensification and expansion of ionospheric electrojet currents results in rapidly changing magnetic flux at ground level which can induce damaging emfs and resultant currents in ground equipment, especially when substorm expansions occur in association with geomagnetic storms. Predictive ability with regard to onset of substorm expansions will depend on our understanding the initiation mechanism.

\section{Development of Substorm Models}

As we entered this quadrennial period, several substorm models had been put forth. Each described an observed substorm process, and owing to ambiguities in the timing and mapping of substorm features, each could stake claim to being the description of the substorm.

\subsection{M-I Coupling Models}

It was not long after the identification of the substorm as a distinct phenomenon $[A$ kasofu, 1964] that the earliest substorm models were introduced involving magnetosphere-ionosphere (M-I) coupling or reconnection (magnetic merging). The M-I coupling models evolved from models to describe auroral arc intensification and expansion [e.g., Heppner et al., 1967; Coroniti and Kennel, 1972] in which the power supplied by magnetospheric convection was either implicitly or explicitly assumed. Later versions of these models include those of $Z h u$ and Kan [1990], who model Alfvén wave transmission between ionosphere and magnetosphere including precipitative enhancements of conductance, and Rothwell et al. [1988; 1991], who model the circuit analogy, including fieldaligned potential drops. Auroral arc brightening and expansion results from the interplay of Hall and Pedersen conductance gradients. In the $\mathrm{Zhu}$ and Kan model, apart from an initial electric field pattern imposed on the ionosphere, the magnetosphere is passive, represented by reflection coefficients between -1 (open field lines) and +1 (sub-auroral, closed field lines). In the Rothwell et al. model, the substorm emf is assumed which powers auroral breakup.

\subsection{The Near-Earth Neutral Line Model}

Within the open-magnetosphere model [Dungey, 1961], reconnection in the geomagnetic tail was recognized early-on as a mechanism to power substorm expansions. Atkinson [1967] assumed impulsive reconnection at the far-tail neutral line and resulting earthward flow of flux tubes to explain geomagnetic 
bays and the pile-up of these flux tubes near Earth to explain the auroral bulge observed during substorms. Based on stress-balance arguments, Siscoe and Cummings [1969] argued the need for reconnection to occur near Earth. McPherron et al. [1973] presented an observationally-based description of the substorm which emphasized the substorm current wedge resulting from local current disruption initiated near Earth in a thin current sheet. They suggested that the current disruption might have resulted from neutral-line formation. Hones et al. [1973] observed that while the plasma sheet expanded (dipolarized) near Earth, the mid-tail plasma sheet dropped out (thinned) only to reappear later (at substorm recovery) in association with fast earthward flows. They suggested that these observations were consistent with near-Earth neutral line (NENL) formation at about 10-15 $R_{E}$ (Earth radii) in the tail at substorm expansion onset and its retreat downtail at substorm recovery. Their observations were summarized by the Hones' cartoon [Hones, 1977]. Theoretically, Schindler [1974] suggested that the geotail was unstable to the growth of the collisionless ion tearing instability leading to neutral-line formation. However, it appeared that the collisionless ion tearing mode was stabilized by electron magnetization unless the wavelength of the mode were unrealistically long. (See the discussion by Coroniti [1985].) In the NENL model, the ionosphere is passive; substorm onset results from an instability internal to the plasma sheet. For almost two decades the NENL model was the leading substorm model because (1) it most clearly encompassed most of the morphology of substorms as it was perceived, (2) invoked magnetic merging to account for substorm power, and (3) had predicted the occurrence of plasmoids, i.e., tailward flowing closed magnetic loops disconnected from Earth, which were indeed observed in the far tail (see \$2.4). Work has progressed detailing the dynamics of the NENL model through the MHD simulations of Birn and Hesse [e.g., Birn and Hesse, 1991; Hesse and Birn, 1994] and Lyon and Fedder [e.g., Lyon and Fedder, 1994].

\subsection{The Rarefaction Model}

Observational evidence for the NENL model did not go unquestioned. Lui et al. $[1977 a, b]$ argued that observed plasma flows in the geomagnetic tail within $\sim 30 R_{E}$ were predominently earthward and that the occurrence of southward field near Earth, as would be expected in connection with a near-Earth neutral line, merely resulted from the southward tilting of strong taillike field lines (consistent with the results of a later survey by Fairfield et al. [1987]). Chao et al. [1977] offered the rarefaction wave model as an alternative explanation for the Hones et al. observations. In this model, feedback from electrojet enhancement in the Coroniti-Kennel model on plasma flows near the inner edge of the plasma sheet causes the inner part of the plasma sheet to lurch earthward, launching a rarefaction down the tail which would result in deflation, i.e., the expansion phase thinning of the plasma sheet. An alternative to the NENL model was thus available. Either substorm onset was the result of $\mathrm{M}$ I coupling with the tail responding, or onset resulted from onset of reconnection near Earth. This evolved into a debate of whether substorm expansion was directly driven by the solar wind-magnetosphere interaction via $\mathrm{M}$-I coupling or resulted from an unloading phenomenon resulting from instability internal to the magnetotail.

However, in the Chao et al. model the plasma was assumed adiabatic; the predicted thinning was significantly less than observed. Also, while the energy available in the closed-field-line plasma sheet is sufficient to account for the energy dissipated in the ionosphere during substorms (if we do not also have to account for plasmoids), it was merely an assumption that the plasma sheet could deflate fast enough to account for substorm power. Later calculations would show that unless ions could somehow be released (demagnetized) or deenergized, plasma compression would prevent rapid earthward transport of magnetic flux from downtail and dipolarization of stressed plasma-sheet flux tubes [e.g., Erickson and Wolf, 1980; Schindler and Birn, 1982] - the so-called "pressure-balance inconsistency" argument. Indeed, plasma compression causes the earthward return rate of flux transport in the plasma sheet to lag the dayside reconnection rate. Thus, this argument complemented the stress-balance argument of Siscoe and Cummings [1969] in providing an explanation as to why plasma and magnetic flux is stored in the tail, only to be released in sporadic events, namely substorms.

\subsection{Boundary-Layer Models}

Notwithstanding the lack of direct observational support for reconnection near Earth, ISEE-3 observations of substorm-associated plasmoids in the far tail [Hones et al., 1984] provided support for the NENL model. Meanwhile, ISEE-1 observations clarified the properties of the plasma-sheet boundary layer 
(PSBL) bordering the central plasma sheet [e.g., Eastman et al., 1984]. In a study of auroral precipitation morphology, Winningham et al. [1975] had classified diffuse (unaccelerated and unstructured) precipitation as CPS ("central plasma sheet") type and discrete (structured by field-aligned acceleration) BPS ("boundary plasma sheet") type. The same characterization can be applied to the isotropic central plasma sheet plasma and the beam-like distributions in the PSBL. Winningham et al.'s BPS is associated with arcs and auroral expansions, and during the course of substorm expansion the aurora do involve boundary-layer associated behavior. This added fuel to the directly driven versus unloading debate. While a natural explanation associated the PSBL with the separatrix mapping to an $\mathrm{X}$-type neutral line separating the closed plasma sheet and the open tail-lobe field lines, owing to a lack of near-Earth reconnection signatures, various boundary-layer models were put forth as substorm mechansims [e.g., Rostoker and Eastman, 1987; Goertz and Smith, 1989]. To the debate over whether the substorm was directly driven or an unloading phenomenon entered confusion over the timing and mapping of substorm processes. One model was suggested by Lyons and Nishida [1988] which included onset of reconnection within the equatorial source of the BPS, mistakenly equated with the PSBL. Generally regarded as a boundary-layer model for substorm expansion, this model might be more appropriately called a "not-so-near-Earth neutral-line" model.

\subsection{The Current Disruption Model}

Out of chaos would come order, but there is one more piece of the substorm puzzle to set the stage for the progress of this quadrennial. Kaufmann [1987] demonstrated that the growth-phase stretching of the magnetic field at geosynchronous distance required an intense current sheet between 7 and $10 R_{E}$, moreso than had previously been appreciated. Shortly thereafter, results from the AMPTE satellite missions with their near-equatorial orbit and fast sampling rates began to be reported. Lui et al. [1988] reported observations of magnetic field turbulence in association with dipolarization in the near-Earth plasma sheet. A current disruption theory for substorm onset based on a cross-field current instability (CFCI) was offerred [ $L u i$ et al., 1990]. In this theory, as the current drift speed in the current sheet neared the local sound speed, kinetic instability would ensue, resulting in electromagnetic turbulence which disrupts the current. Multi- satellite observations involving AMPTE and geosynchronous satellites [e.g., Lopez and Lui, 1990] show the close association in time between first signs of onset in the near-Earth plasma sheet and ground onset. Such observations are consistent with earlier observations by McPherron et al. [1973], Nagai [1982] and others which show local development of a substorm current wedge and subsequent expansion both radially and in local time. Baumjohann et al. [1990] showed that within AMPTE/IRM apogee $\left(\sim 19 R_{E}\right)$, fast flows are predominantly earthward, and tailward flows are infrequent, consistent with the earlier findings of $L u i$ et al. [1977b]. If an X-line forms in association with substorms, it would appear that it usually forms tailward of $19 R_{E}$.

\section{Consensus on Substorm Morphology}

The success of the AMPTE, ISEE, and Viking satellite missions in concert with ground and geosynchronous observations and the improved magnetic field models of Tsyganenko [1987, 1989] clarified many of the issues surrounding the location and timing of substorm processes. A new consensus on the spatial relationship between ionosphere and magnetosphere was reached in accord with the review by Galperin and Feldstein [1991]. Highlighting the new consensus was the recognition that the low-latititude extent of the BPS, which contained the equatorwardmost arc which intensified at substorm onset, maps close to Earth and away from the boundary layers. A synthesis was presented by $L u i$ [1991], namely, the near-Earth current disruption (NECD) model (paraphrased below) in which the various substorm processes, and associated models, were unified consistent with observed morphology.

\subsection{The Near-Earth Current Disruption Model}

During the substorm growth phase, magnetic flux in the tail increases, the auroral oval expands, the inner edge of the plasma sheet moves earthward, and cross-tail current increases. In the near-Earth plasma sheet, the current sheet thins to the order of average proton gyroradii, and the current drift speed approaches the local sound speed. Convection during the growth phase maintains the prebreakup arc magnetically connected to the near-Earth plasma sheet.

Substorm expansion onset occurs as the near-Earth cross-tail current is suddenly substantially reduced locally in both radial and local-time extent. (The growth-phase current sheet is thicker away from the 
near-Earth, midnight sector.) Cross-tail current shunts around the disruption region along magnetic field lines and westward through the ionosphere as the substorm current wedge. Within the wedge, previously stressed magnetic field dipolarizes consistent with a large dawn-to-dusk induction electric field which injects plasma earthward. A rarefaction is launched which thins the current sheet as it propagates, and the current disruption region may expand.

Current-sheet thinning, the disruption region, and current wedge may spread longitudinally as well in a combination of three ways: (1) longitudinal propagation of the rarefaction wave, (2) negative northsouth perturbation magnetic field outside the current wedge, and (3) continuation of the growth-phase magnetic field stressing east and west of the disruption region. Depending on a variety of factors, the current wedge could expand more or less smoothly away from the initial disruption region, or several longitudinal sectors of the near-Earth current sheet could disrupt in a rather haphazard fashion and be observed as multiple substorm intensifications. Alternatively, the disruption may remain local resulting in a "pseudobreakup".

Velocity shear along the eastward and westward edges of the convection surge and rarefaction wave can result in onset of velocity-shear instability. As well, as the rarefaction reaches the low-latitude boundary layer, strong velocity shear may result to yield multiple surge forms and auroral vortices. Plasma depletion tailward of the convection surge launches the rarefaction resulting in a radially extended thin plasma sheet which may be unstable to tearing and neutralline formation. One or more plasmoids may form to be ejected downtail.

\subsection{The Kiruna Consensus}

At the First International Conference on Substorms held at Kiruna observed substorm phenomena were reviewed leading to the community consensus, known as the "Kiruna conjecture", that "the auroral substorm onset is closely coupled to events in the geosynchronous region" [Kennel, 1992]. Cogger and Elphinstone [1992] showed results from Viking imagery confirming the new consensus on the timing and mapping of substorm phenomena. As well many presentations were given demonstrating both a directly driven and unloading component of substorms [e.g., Baker, 1992]. After Kiruna, advocacy for the boundary-layer models for the substorm diminished. Even Larry Lyons, one of the most ardent proponents of a boundary-layer origin for substorms, is now a champion of near-Earth onset [e.g., Samson et al., 1992]. As well, advocates of a directly driven nature of substorms now admit that M-I coupling models are missing an unloading component [Kan, 1992].

A strong impression was given at the Kiruna meeting that the magnetospheric community now accepts that substorm onset occurs locally near Earth, in the absence of apparent reconnection signatures, and its effects expand radially and in local time, as well as the Galperin-Feldstein renaissance. Indeed, many researchers subscribe to the "strong version" of the Kiruna conjecture that "plasma sheet reconnection and plasmoid formation do not always have to occur in close temporal and spatial proximity to the events defining the geosynchronous substorm" [Kennel, 1992]. In its strong version, the Kiruna conjecture favors the NECD model of substorms. However, case studies exist in which observations appear consistent with neutral-line formation near Earth in close association with ground onset and its tailward retreat, including tailward then earthward bulk plasma flow [e.g., Fritz et al., 1984]. Advocates for the NENL model suggest that much of the evidence against nearEarth reconnection at substorm onset is statistical in nature; even if the NENL model were the correct description of most substorms, owing to the thinness of the current sheet, the localness of onset, and the sparseness of observations, only in a minority of events would clear neutral-line signatures be observed. The reader is referred to the review by Siscoe [1993] for additional discussion of the NECD and NENL models.

\section{Theories for Expansion Phase Onset}

In this quadrennial we have witnessed the rise of the NECD model to rival the NENL model as the leading model for the substorm, while directly driven and boundary-layer models appear untenable. However, the mechanism of substorm expansion onset is still undetermined. Weimer [1994] shows that the electrojets $(A E)$ follow an exponential growth and decline during substorm expansion and recovery. Moldwin and Hughes [1993] show an approximate one-toone correspondence between plasmoids observed in the far tail and earlier ground onsets. As well as the power involved in substorm expansions, these observations argue for unloading of previously stored plasma and magnetic flux in the tail. However, theories for mechanisms of current-sheet instability face 
both theoretical and observational difficulties.

\subsection{The Tearing Mode}

The close temporal relationship between events at geosynchronous and ground onset does not rule out the tearing mode, or some other global instability, as the cause of substorm onset. If onset results from a large-scale instability, then the plasma sheet near geosynchronous and $20-30 R_{E}$ downtail can go unstable together. However, as theoretical analysis of the collisionless tearing mode advances, its feasibility as the mechanism of substorm expansion onset is becoming more doubtful. Energy-principle analysis, particle simulations and hybrid simulations all indicate the magnetotail to be stable against collisionless tearing.

Energy-principle analysis by Wang and Bhattacharjee [1993] showed the magnetotail to be stable against ion tearing even in the presence of a magnetic shear $B_{y}$ component. However, they left open the possibility that the electron tearing instability can grow in the presence of a significant shear component. Pellat et al. [1991] and Brittnacher et al. [1994] used energy-principle analysis to show that even strong electron pitch-angle diffusion cannot remove strong stabilization of the tearing mode caused by electron compression. Particle simulations by Pritchett [1994] and Pritchett and Büchner [1994] confirm these results. Pritchett and Büchner included a minimum (as small as zero) in equatorial magnetic field strength and a shear $B_{y}$ component, both observed in the nearEarth current sheet [e.g., Sergeev et al., 1993]. Winske and Hesse [1994] found the collisionless tearing mode to be stable in hybrid simulations containing realistic ion-to-electron mass ratio. It must be noted, however, that analysis has been mainly limited to two dimensions. It is possible that stabilization of collisionless tearing owing to electron compressibility might be removed by particle loss, or through three-dimensional effects such as M-I coupling and violation of canonical $p_{y}$ momentum, which is conserved in two dimensions. Another possibility is that anomalous resistivity resulting from the CFCI (see below) permits resistive tearing to proceed. Given the observation of substorm-associated plasmoids, neutral-line formation seems to occur at some point during substorm expansions.

\subsection{The CFCI}

Quasi-linear analysis in local approximation by $L u i$ et al. [1993] has shown the CFCI to have growth rates fast enough for the suddenness of substorm onset. However, first results of non-local analysis of a CFCI mechanism by Chang et al. [1994] indicates stabilization in high- $\beta$ plasma. Hesse and Birn [1993] and Erickson [1993] argue that the CFCI is a driven process. This is not at odds with the scenario presented by $L u i$ et al. [1991] whereby the CFCI results as, during the growth phase, the current sheet thins to ion gyroradius scalelength, and ions become unmagnetized to undergo large drifts across the tail. Observations of current disruptions in the near-Earth plasma sheet appear consistent with disruption owing to the CFCI as described by Lui and colleagues, including wave power near the ion cyclotron frequency [e.g., Lui et al., 1992]. Indeed, a rapid ( $\sim 1$ minute), several-n $\mathrm{T}$ depression of the magnetospheric $\mathrm{H}$ component was observed at AMPTE/CCE just prior to local dipolarizations by Ohtani et al. [1992] (when the satellite was located earthward of the subsequent current disruption). This "explosive growth phase" is also frequently observed at CRRES just prior to dipolarizations associated with local substorm onsets. Ohtani et al. interpret this as resulting from an explosive enhancement in tail current intensity just prior to current disruption.

Observations of a thin current sheet prior to dipolarization have not revealed a distinction, inherent to the sheet, between thin current sheets which persist for tens of minutes [e.g., Pulkinnen et al., 1992], undergo current disruption resulting in pseudobreakup [e.g., Ohtani et al., 1993], or undergo current disruption which expands into a substorm. Sergeev et al. [1994] have inferred a magnetotail configuration during steady magnetospheric convection (SMC) events consistent with the steady-state equilibrium models of Hau [1991]. The SMC configuration exhibits a deep minimum in equatorial magnetic field strength and intense, thin current sheet near Earth, as severe or more than any observed prior to substorm onset. Thin current sheets appear remarkably stable at times, prompting Sergeev et al. [1994] to ask in regard to their SMC observations: "How can such a stressed configuration with such a thin and intense current sheet in the near-Earth tail remain stable during many hours?" An interesting idea advocated by this researcher is that the CFCI actually maintains the large-scale stability of thin current sheets in the presence of modest growth-phase electric fields. As the current sheet gradually thins to the point where ions begin to unmagnetize, the CFCI growth rate increases, scatters the ions, and ions remagnetize. Thus 
under the action of the modestly driven CFCI, the current drift velocity is limited somewhat below the ion thermal speed and the current sheet thickness near ion gyroradii. An additional "kick" provided by a solar-wind trigger or, perhaps, by the evolution of the M-I coupling is needed to reduce the currentsheet thickness below ion gyroradii. If this occurs the CFCI growth rate can increase substantially, and the current sheet might destabilize in the presence of the enhanced anomalous resistivity.

\section{The Role of M-I Coupling}

There have been various suggestions on a role for $M-I$ coupling in destabilizing the near-Earth current sheet, permitting substorm expansion to proceed.

\subsection{The Ionospheric Closure Condition}

$L u i$ [1991] and colleagues studying current disruptions in the near-Earth plasma sheet suggest that local current disruption originating in the current sheet may or not expand depending on the ability of the ionosphere to carry the diverted current. Consider what can happen assuming that a local current disruption occurs. A portion of the cross-tail current must divert around the disruption region either earthward, tailward, or along magnetic field lines to close through the ionosphere. Within the disruption region, plasma is heated and diffuses; the magnetic configuration is altered in the vicinity of the disruption region. It is difficult to ascertain how the diamagnetic drift current is altered about the disruption region.

Let's suppose that the disrupted current does not divert earthward or tailward around the disruption region. Rather, charge accumulates at the edges of the disruption region, enhances the westward electric field and launches an Alfven wavefront toward the ionosphere carrying the disrupted current. Prior to the Alfven wavefront reaching the ionosphere, growthphase sized electric fields and electrojets existed. As the Alfvén wavefront reaches the ionosphere, charge will accumulate to enhance the (westward) electric field; the (westward) electrojet will increase owing to the enhanced electric field - and as Joule heating and precipitation from the disruption region raises the conductivity - until the electrojet is enhanced to carry the disrupted current. Thus, Lui's current disruption model with the ionospheric closure condition is the modern version of the rarefaction wave model of Chao et al. [1977] discussed in \$2.3. Since the work of Kaufmann [1987] and others, we now know that the near-Earth, pre-onset current sheet is much more intense and thin than had been previously appreciated. With current-sheet thickness near typical proton gyroradii, proton adiabaticity can be violated if the sheet is forced to thin further.

\subsection{Ionospheric Overloading}

Kan [1993] suggests that current disruption associated with substorm onset might be triggered by the eastward polarization current in an Alfvén wavefront launched from the ionosphere. An Alfven wavefront carrying an eastward polarization current and eastward polarization electric field can be launched from the ionosphere when westward electrojet current increases faster than field-aligned current is being provided from the magnetosphere. This might happen as the equatorial curvature of field lines increases during the growth phase, and, e.g., $L$-shell splitting occurs at the boundary of trapped energetic electrons ( $>30$ $\mathrm{keV}$ ). These electrons isotropize and some scatter into the loss cone (see e.g., West [1979] and Pulkkinen et al. [1992]). These energetic electrons can reach E-region altitudes, and each can produce many ionelectron pairs (one pair per $35 \mathrm{eV}$ of incident energy). These electrons are super-Alfvénic so the ionospheric current can increase, for a given imposed westward electric field, faster than field-aligned current is being provided by the magnetosphere. The ionosphere becomes polarized as positive (negative) space charge accumulates at the westward (eastward) end of the conductive strip. To equilibriate the charge along field lines, an Alfvén wavefront is launched to transmit the eastward polarization electric field into the magnetosphere. Behind the eastward (westward) side of the wavefront is upward (downward) field-aligned current. The $E \times B$ velocities of field lines slow as the Alfvén wavefront propagates. Along the wavefront is an eastward polarization (inertial) current. The equatorward ends of the field lines convect at the unperturbed $\mathrm{E} \times \mathrm{B}$ velocity until the wavefront arrives there. During the transit time of the wavefront from ionosphere to equatorial magnetosphere, the field lines become more dipolar reducing their curvature, and the $E \times B$ speed has been slowed. This reduces or turnsoff the source of the energetic electrons which started the process.

This mechanism is the explanation for auroral fading given by Pellinen and Heikkila [1978]. As ionizing precipitation causes an electrojet to intensify, ionospheric feedback results in the braking of convection and the reduction of the ionization source. (Pellinen 
and Heikkila note that during auroral fading fluxes of precipitating ions and electrons behave similarly.) While the slowing of convection hardly seems like a substorm onset trigger, nevertheless, auroral fading is a common occurrence just prior to onset, and we cannot know how the nearby current sheet responds to this dipolarization until we test this mechanism in a global MHD code. The response could be minor, or the dipolarization could launch waves resulting in current-sheet thinning downtail.

\subsection{Mass Exchange}

Motivated by detailed particle and field observations at geosynchronous orbit, Roux et al. [1991] suggested the ballooning instability as the mechanism for substorm onset. At the Second Internationational Conference on Substorms held at Fairbanks this past year, several presentations were given supportive of some sort of ballooning scenario for substorm onset. Conventional ballooning is stabilized by compression of the plasma as flux tubes alter their volumes. Very special conditions are required if conventional ballooning is to be unstable in the near-Earth plasma sheet. Whether or not such conditions exist is an issue of debate [e.g., Pu et al., 1992; Ohtani and Tamao, 1993; Lee and Wolf, 1992]. (The ballooning discussed here and below is not the usual short-wavelength perturbation; rather, long wavelengths are considered in which the fundamental mode consists of a halfwavelength between conjugate ionospheres.)

Based upon MHD energy-principle analysis of twodimensional, quasi-static equilibrium models of growthphase convection, modified ballooning scenarios have been suggested as substorm onset triggers. The modification is to take account of the exchange of mass between ionosphere and the near-Earth plasma sheet. The suggestion is that stabilization provided by plasma compression can be nullified by precipitation of energetic ions into the ionosphere - the "ideal tearing mode" description of Birn et al. [1994], or via redistribution of ion pressure along field lines in association with growth of field-aligned potential drops - the "global ballooning" description of Erickson and Heinemann [1992]. In either scenario, the normal-mode, inward/outward oscillation of plasmasheet flux tubes can overshoot their equilibrium position. The pressure distribution along near-Earth plasma-sheet flux tubes adjusts to the requirements of M-I coupling on a timescale faster than the global, growth-phase, quasi-static equilibrium evolves. The suggestion is that a pressure distribution consistent with M-I coupling can evolve near-Earth which is inconsistent with the slowly evolving growth-phase equilibrium. This puts the near-Earth plasma sheet out of equilibrium with the tail lobes, resulting in forced thinning of the near-Earth plasma sheet. This launches a rarefaction wave and drives a currentdisruption mechanism, the CFCI and/or tearing. As with the other suggested roles of M-I coupling in substorm onset, this mechanism needs detailed modeling and testing in a global context.

\section{Summary}

During this quadrennial we have seen the rise of the near-Earth current disruption (NECD) model to rival the near-Earth neutral line (NENL) model as the leading model for the substorm. In the NECD model, substorm expansion onset occurs in the near-Earth portion of the nightside plasma sheet as stressed magnetic field dipolarizes. Substorm-associated boundarylayer processes evolve as a consequence of substorm expansion. As well, in the NECD model magnetic neutral-line formation is regarded to result from substorm expansion, rather than to be responsible for its onset.

What triggers onset of substorm expansion is still undetermined. Possible mechanisms are growth of an ion tearing mode, current disruption by a cross-field current instability, and magnetosphere-ionosphere coupling. A thin current sheet, favorable to chaotization of particle orbits, demagnetization of ions, and the growth of a cross-field current instability or the ion tearing mode, is observed in the near-Earth plasma sheet prior to dipolarization. Yet, recent advancements of these onset theories are revealing these mechanisms to be stable or to have growth rates which are too slow unless driven. Furthermore, a thin current sheet can persist for tens of minutes, in some cases hours, prior to local dipolarization, and not all local dipolarizations evolve into full-fledged substorm expansions. A current-sheet instability is needed to account for the rapid return transport of magnetic flux associated with substorm expansions as well as for plasmoid formation and release. The notion that magnetosphere-ionosphere coupling plays a role in triggering current-sheet instability and substorm expansion onset is gaining support. It appears that M-I coupling, cross-field current instability, and tearing operate in concert to result in substorm expansions. 
Acknowledgments This work was supported by NASA under grants NAGW-2627 and NAGW-2856, and the U.S. Air Force under contract F19628-90-K0003 .

\section{References}

Akasofu, S.-I., The development of the auroral substorm, Planet. Space Sci., 12, 273, 1964.

Atkinson, G., Polar magnetic substorms, J. Geophys. Res., 72, 1491, 1967.

Baker, D. N., Driven and unloading aspects of magnetospheric substorms, in Substorms 1, pp. 185-191, ESA SP-335, May 1992.

Baumjohann, W., G. Paschmann, and H. Lühr, Characteristics of high-speed ion flows in the plasma sheet, J. Geophys. Res., 95, 3801, 1990.

Birn, J., and M. Hesse, The substorm current wedge and field-aligned currents in MHD simulations of magnetotail reconnection, J. Geophys. Res., 96, 1611, 1991.

Birn, J., K. Schindler, L. Janicke, and M. Hesse, Magnetotail dynamics under isobaric constraints, J. Geophys. Res., 99, 14,863, 1994.

Brittnacher, M., K. B. Quest, and H. Karimabadi, On the energy principle and ion tearing in the magnetotail, Geophys. Res. Lett., 21, 1591, 1994.

Chang, C. L., A. T. Y. Lui, and P. H. Yoon, Nonlocal stability analysis of the current driven instabilities in magnetotail, $E O S$ Trans. $A G U, 75$, no. 16 supplement, 308, 1994.

Chao, J. K., J. R. Kan, A. T. Y. Lui, and S.-I. Akasofu, A model for thinning of the plasma sheet, Planet. Space Sci., 25, 703, 1977.

Cogger, L.L., and R. D. Elphinstone, The Viking auroral substorm, in Substorms 1, pp. 77-82, ESA SP-335, May 1992.

Coroniti, F. V., Explosive tail reconnection: the growth and expansion phases of magnetospheric substorms, J. Geophys. Res., 90, 7427, 1985.

Coroniti, F. V., and C. F. Kennel, Polarization of the auroral electrojet, J. Geophys. Res., 77, 2835, 1972.

Dungey, J. W., Interplanetary magnetic field and the auroral zones, Phys. Rev. Lett., 6, 47, 1961.

Eastman, T. E., L. A. Frank, W. K. Peterson, and W. Lennartsson, The plasma sheet boundary layer, $J$. Geophys. Res., 89, 1553, 1984.
Erickson, G. M., Substorm theories: are they converging, in Stategies for the Tail and Substorm Campaign, edited by W. J. Hughes, pp. 45-64, Boston University Center for Space Physics, Boston, 1993.

Erickson, G. M., and M. Heinemann, A mechanism for magnetospheric substorms, in Substorms 1, pp. 587-592, ESA SP-335, May 1992.

Erickson, G. M., and R. A. Wolf, Is steady convection possible in the Earth's magnetotail, Geophys. Res. Lett., 7, 897, 1980.

Fairfield, D. H., M. H. Acuna, L. J. Zanetti, and T. A. Potemra, The magnetic field of the equatorial magnetotail: AMPTE/CCE observations at $\mathrm{R}<$ $8.8 \mathrm{R}_{E}, J$. Geophys. Res., 92, 7432, 1987.

Fritz, T. A., D. N. Baker, R. L. McPherron, and W. Lennartsson, Implications of the $1100 \mathrm{UT}$ March 22,1979 CDAW 6 substorm for the role of magnetic reconnection in the geomagnetic tail, in Magnetic Reconnection in Space and Laboratory Plasmas, Geophys. Monogr. Ser., vol. 30, edited by E. W. Hones, Jr., pp. 203-207, AGU, Washington, D. C., 1984 .

Galperin, Yu. I., and Ya. I. Feldstein, Auroral luminosity and its relationship to magnetospheric plasma domains, in Auroral Physics, edited by C.I. Meng, M. J. Rycroft, and L. A. Frank, pp. 207222, Cambridge University Press, 1991.

Goertz, C. K., and R. A. Smith, The thermal catastrophe model of substorms, J. Geophys. Res., 94, $6581,1989$.

Hau, L.-N., Effects of steady state adiabatic convection on the configuration of the near-Earth plasma sheet, 2, J. Geophys. Res., 96, 5591, 1991.

Heppner, J. P., M. Sugiura, T. L. Skillman, B. G. Ledley, and $M$. Campbell, OGO-A magnetic field observations, J. Geophys. Res., 72, 5417, 1967.

Hesse, M., and J. Birn, On the energy budget in the current disruption region, Geophys. Res. Lett., 14, $1451,1993$.

Hesse, M., and J. Birn, MHD modeling of magnetotail instability for localized resistivity, $J$., Geophys. Res., 99, 8565, 1994.

Hones, E. W., Jr., Substorm processes in the magnetotail: comments on 'On hot tenuous plasmas, fireballs, and boundary layers in the Earth's magnetotail' by L. A. Frank, K. L. Ackerson, and R. P. Lepping, J. Geophys. Res., 82, 5633, 1977. 
Hones, E. W., Jr., J. R. Asbridge, S. J. Bame, and $\mathrm{S}$. Singer, Substorm variations of the magnetotail plasma sheet from $X_{s m}=-6 R_{E}$ to $X_{s m}=$ $-60 R_{E}, J$. Geophys. Res., 78, 109, 1973.

Hones, E. W., Jr., D. N. Baker, S. J. Bame, W. C. Feldman, T. J. Gosling, D. J. McComas, R. D. Zwickl, J. A. Slavin, E. J. Smith, and B. T. Tsurutani, Structure of the magnetotail at $220 R_{E}$ and its response to geomagnetic activity, Geophys. Res. Lett., 11, 5, 1984.

Kan, J. R., A global model of the substorm current system, Geophys. Res. Lett., 19, 969, 1992.

Kan, J. R., A global magnetosphere-ionosphere coupling model of substorms, J. Geophys. Res., 98, $17,263,1993$.

Kaufmann, R. L., Substorm currents: growth phase and onset, J. Geophys. Res., 92, 7471, 1987.

Kennel, C. F., The Kiruna conjecture: the strong version, in Substorms 1, pp. 599-601, ESA SP-335, May 1992.

Lee, D.-Y., and R. A. Woif, Is the Earth's magnetotail balloon unstable, J. Geophys. Res., 97, 19,251, 1992.

Lopez, R. E., and A. T. Y. Lui, A multi-satellite case study of the expansion of a substorm current wedge in the near-Earth magnetotail, J. Geophys. Res., $95,8009,1990$.

Lui, A. T. Y., A synthesis of magnetospheric substorm models, J. Geophys. Res., 96, 1849, 1991.

Lui, A. T. Y., C.-I. Meng, and S.-I. Akasofu, Search for the magnetic neutral line in the near-Earth plasma sheet, 2, Systematic study of Imp 6 magnetic field observations, J. Geophys. Res., 82, 1547, $1977 a$.

Lui, A. T. Y., L. A. Frank, K. L. Ackerson, C.I. Meng, and S.-I. Akasofu, Systematic study of plasma flow during plasma sheet thinning, J. Geophys. Res., 82, 4815, $1977 b$.

Lui, A. T. Y., R. E. Lopez, S. M. Krimigis, R. W. McEntire, L. J. Zanetti, and T. A. Potemra, A case study of magnetotail current disruption and diversion, Geophys. Res. Lett., 15, 721, 1988.

Lui, A. T. Y., A. Mankofsky, C. L. Ghang, K. Papadopoulos, and C. S. Wu, A current disruption mechanism in the neutral sheet: a possible trigger for substorm expansions, Geophys. Res. Lett., 17, $745,1990$.
Lui, A. T. Y., C.-L. Chang, A. Mankofsky, H.-K. Wong, and D. Winske, A cross-field current instability for substorm expansion, J. Geophys. Res., $96,11,389,1991$.

Lui, A. T. Y., R. E. Lopez, B. J. Anderson, K. Takahashi, L. J. Zanetti, R. W. McEntire, T. A. Potemra, D. M. Klumpar, E. M. Greene, and R. Strangeway, Current disruptions in the near-Earth neutral sheet region, J. Geophys. Res., 97, 1461, 1992.

Lui, A. T. M., P. H. Yoon, and C.-L. Chang, Quasilinear analysis of ion Weibel instability in Earth's neutral sheet, J. Geophys. Res., 98, 153, 1993.

Lyon, J. G., and J. A. Fedder, Global simulation of a southward turning of the IMF and its comparison with substorm morphology, Geophys. Res. Lett., (submitted), 1994.

Lyons, L. R., and A. Nishida, Description of substorms in the tail incorporating boundary layer and neutral line effects, Geophys. Res. Lett., 15, 1337, 1988.

McPherron, R. L., C. T. Russell, and M. P. Aubry, Satellite studies of magnetospheric substorms on August 15, 1968. Phenomenological model for substorms, J. Geophys. Res., 78, 3131, 1973.

Moldwin, M. B., and W. J. Hughes, Geomagnetic substorm association of plasmoids, J. Geophys. Res., $98,81,1993$.

Nagai, T., Observed magnetic substorm signatures at synchronous altitude, J. Geophys. Res., 87, 4405, 1982.

Ohtani, S.-I., and T. Tamao, Does the ballooning instability trigger substorms in the near-Earth magnetotail, J. Geophys. Res., 98, 19,369, 1993.

Ohtani, S., K. Takahashi, L. J. Zanetti, T. A. Potemra, R. W. McEntire, and T. Iijima, Initial signatures of magnetic field and energetic particle fluxes at tail reconfiguration: explosive growth phase, J. Geophys. Res., 97, 19,311, 1992.

Ohtani, S., B. J. Anderson, D. G. Sibeck, P. T. Newell, L. J. Zanetti, T. A. Potemra, K. Takahashi, R. E. Lopez, V. Angelopoulos, R. Nakamura, D. M. Klumpar, and C. T. Russell, A multisatellite study of a pseudo-substorm onset in the near-Earth magnetotail, J. Geophys. Res., 98, 19,355, 1993.

Pellat, R., F. V. Coroniti, and R. L. Pritchett, Does ion tearing exist, Geophys. Res. Lett., 18, 143, 1991. 

Pellinen, R. J., and W. J. Heikkila, Observations of auroral fading before breakup, J. Geophys. Res., $83,4207,1978$.

Pritchett, P. L., Effect of electron dynamics on collisionless reconnection in two-dimensional magnetotail equilibria, J. Geophys. Res., 99, 5935, 1994.

Pritchett, P. L., and J. Büchner, Collisionless reconnection in configurations with a minimum in the equatorial magnetic field and with magnetic shear, J. Geophys. Res. (accepted), 1994.

Pu, Z. Y., A. Korth, and G. Kremser, Plasma and magnetic field parameters at substorm onset derived from GEOS 2 observations, J. Geophys. Res., 97, 19,341, 1992.

Pulkkinen, T. I., D. N. Baker, R. J. Pellinen, J. Büchner, H. E. J. Koskinen, R. E. Lopez, R. L. Dyson, and L. A. Frank, Particle scattering and current sheet stability in the geomagnetic tail during the substorm growth phase, J. Geophys. Res., 97, 19,283, 1992.

Rostoker, G., and T. Eastman, A boundary layer model for the magnetospheric substorms, J. Geophys. Res., 92 12,187, 1987.

Rothwell, P. H., L. P. Block, M. B. Silevitch, and C.G. Fälthammar, A new model for substorm onsets: the pre-breakup and triggering regimes, Geophys. Res. Lett., 15, 1279, 1988.

Rothwell, P. H., M. B. Silevitch, L. P. Block, and C.G. Fälthammar, Pre-breakup arcs: a comparison between theory and experiment, J. Geophys. Res., $96,13,967,1991$.

Roux, A., S. Perraut, P. Robert, A. Morane, A. Pedersen, A. Korth, G. Kremser, B. Aparicio, D. Rodgers, and R. Pellinen, Plasma sheet instability related to the westward traveling surge, J. Geophys. Res., 96, 17,697, 1991.

Samson, J. C., L. R. Lyons, P. T. Newell, F. Creutzberg, and $\mathrm{B}$. $\mathrm{Xu}$, Proton aurora and substorm intensifications, Geophys. Res. Lett., 19, 2167, 1992.

Schindler, K., A theory of the substorm mechanism, J. Geophys. Res., 79, 2803, 1974.

Schindler, K., and J. Birn, Self-consistent theory of time-dependent convection in the Earth's magnetotail, J. Geophys. Res., 87, 2263, 1982.

Sergeev, V. A., D. G. Mitchell, C. T. Russell, and D. J. Williams, Structure of the tail plasma/current sheet at $\sim 11 R_{E}$ and its changes in the course of a substorm, J. Geophys. Res., 98, 17,345, 1993.
Sergeev, V. A., T. I. Pulkkinen, R. J. Pellinen, and N. A. Tsyganenko, Hybrid state of the tail magnetic configuration during steady convection events, $J$. Geophys. Res., 99, 23,571, 1994.

Siscoe, G., Recent activity in substorm research, $A d v$. Space Res., 13, (4)165, 1993.

Siscoe, G. L., and W. D. Cummings, On the cause of geomagnetic bays, Planet. Space Sci., 17, 1765 1969.

Tsyganenko, N. A., Global quantitative models of geomagnetic field in the cislunar magnetosphere for different disturbance levels, Planet. Space Sci., 35, 1347, 1987.

Tsyganenko, N. A., On the re-distribution of the magnetic field and plasma in the near midnight magnetosphere during a substorm growth phase, Planet. Space Sci., 37, 183, 1989.

Wang, X., and A. Bhattacharjee, Global asymptotic equilibria and collisionless tearing stability of magnetotail plasmas, J. Geophys. Res., 98, 19,419, 1993.

Weimer, D. R., Substorm time constants, J. Geophys. Res., 99, 11,005, 1994.

West, H. I., Jr., The signatures of the various regions of the outer magnetosphere in the pitch angle distributions of energetic particles, in Quantitative Modeling of Magnetospheric Processes, Geophys. Mon. 21, edited by W. P. Olson, pp. 150179, American Geophysical Union, Washington DC, 1979 .

Winningham, J. D., F. Yasuhara, S.-I. Akasofu, and W. J. Heikkila, The latitudinal morphology of 10$\mathrm{eV}$ to $10-\mathrm{keV}$ electron fluxes during magnetically quiet and disturbed times in the 2100-0300 MLT sector, J. Geophys. Res, 80, 3148, 1975.

Winske, D., and M. Hesse, Hybrid modeling of collisionless magnetic reconnection in magnetotail configurations, $E O S$ Trans. $A G U, 75$, no. 16 supplement, 305, 1994.

Zhu, L., and J. R. Kan, Effects of ionospheric recombination time scale on the auroral signature of substorms, J. Geophys. Res., 95, 10,389, 1990.

This preprint was prepared with the AGU IATEX macros v3.1. File QUAD94LATEST formatted 1995 January 5. 